\title{
Role of the South China Sea Summer Upwelling in Tropical Cyclone Intensity
}

\author{
Dazhi Xu1 ${ }^{1}$ Chunhua Qiu², Youfang Yan ${ }^{3 *}$ \\ ${ }^{1}$ South China Sea Marine Prediction Center, State Oceanic Administration, Guangzhou, China \\ ${ }^{2}$ The Center for Coastal Ocean Science and Technology, School of Marine Sciences, Sun Yat-sen University, Guangzhou, China \\ ${ }^{3}$ State Key Laboratory of Tropical Oceanography, South China Sea Institute of Oceanology, Chinese Academy of Sciences, \\ Guangzhou, China \\ Email: *youfangyan@scsio.ac.cn
}

How to cite this paper: $\mathrm{Xu}, \mathrm{D} . \mathrm{Z}$., Qiu, C.H. and Yan, Y.F. (2019) Role of the South China Sea Summer Upwelling in Tropical Cyclone Intensity. American Journal of Climate Change, 8, 1-13.

https://doi.org/10.4236/ajcc.2019.81001

Received: October 11, 2018

Accepted: January 21, 2019

Published: January 24, 2019

Copyright (C) 2019 by author(s) and Scientific Research Publishing Inc. This work is licensed under the Creative Commons Attribution International License (CC BY 4.0).

http://creativecommons.org/licenses/by/4.0/

(c) (i) Open Access

\begin{abstract}
Tropical cyclones (TCs) can affect the thermal structure in the upper ocean by mixing. In turn, upper-ocean thermal structure also affects the evolution of TCs. Here based on satellite data, in situ temperature and salinity observations and the best-track data of the U.S. Joint Typhoon Warning Center, combined with an ocean mixed layer model, the role of the pre-existing summer upwelling of the northern South China Sea (NSCS) in TCs self-induced sea surface cooling was explored. The modeling results showed that for a given atmospheric thermodynamic condition, TCs self-induced sea surface cooling is quite different when they pass over the regions with pre-existing upwelling and without upwelling. The amplitude of TCs self-induced cooling is larger by more than $50 \%$ in the region with pre-existing upwelling than that without. For example, for a slow-moving typhoon with translation speed of $4 \mathrm{~m} / \mathrm{s}$ and wind speed of $45 \mathrm{~m} / \mathrm{s}$, TC self-induced surface cooling is $2.5^{\circ} \mathrm{C}$ when they pass over the upwelling region, but only $1.5^{\circ} \mathrm{C}$ when they pass over the region without upwelling. The results suggest that upwelling of the NSCS could amplify TCs self-induced cooling and play a negative role in TCs intensification before they made landfall in Southern China.
\end{abstract}

\section{Keywords}

South China Sea, Summer Upwelling, Tropical Cyclone Intensity

\section{Introduction}

Upwelling, as one of the most important physical processes linking to wind-driven currents and shelf topography in the marginal ocean, is commonly 
characterized by the upward motion induced by the offshore water transport at the surface, and the onshore water transport in the deep layers [1]. Upwelling occurs in many of the world's coastal oceans, and plays a key role in the near-shore ecosystem because it supplies nutrient-rich waters there [2]. Upwelling can also modulate the upper ocean thermal structures and oceanic stratifications by transporting deep waters with high density and salinity, and low temperature to the surface.

The South China Sea (SCS), located at the junction of Indian monsoon, Northwestern Pacific (WNP) monsoon and East Asian monsoon [3], is one of the largest semi-enclosed marginal seas in the northwestern Pacific. During the boreal winter, the northeast monsoon prevails in the SCS, whereas in boreal summer the northeast winds reverse to the southwest. The southwest monsoon would induce offshore Ekman transport and withdraw deep cold water upwell to the surface in the northern SCS [4] [5] [6] [7].

As one of the most prominent and seasonal common phenomenon, upwelling in the NSCS is firstly observed with a more than $1^{\circ} \mathrm{C}$ drop in SST off Vietnam [8] and to the east of Hainan Island during summer monsoon [9]. Using the data of Nationwide Ocean Resource Survey of China for the period of 1959-1960, Guan and Chen [10] systematically investigated the NSCS upwelling and pointed out that there were three main upwelling centers located off the east of Hainan Island, Shantou Coast, and the east of Leizhou Peninsula during the summer. Later on, many studies were carried out to investigate the NSCS upwelling and its dynamic mechanisms using observations and numerical simulations, because it is related not only to chemistry, biology and fisheries, but also to the Pearl River plume, SCS warm currents and Kuroshio branches [4] [6] [7] [11].

As mentioned above, the SCS is one of the largest semi-enclosed marginal seas in the WNP. As an important part of the largest warm pool in the WNP, the NSCS is frequently subject to tropical cyclones (TCs; also known as typhoon). The prevailing tracks of TCs in the WNP and the local SCS are westward and coincide with the summer upwelling in the NSCS. Generally, tracks of TCs are controlled by large-scale atmospheric steering flow [12]. Existing weather prediction models now can make reasonable forecasts of typhoon track [13], but the intensity of typhoon is by comparison much more difficult to forecast. This is because typhoon intensity is not only related to the pre-existing atmospheric conditions but also to the upper ocean [13] [14] [15]. Evidences from numerous studies indicate that typhoon-induced strong vertical ocean mixing can bring deep cold water to the surface, and make sea surface temperature (SST) cooler than the ambient waters by up to $2^{\circ} \mathrm{C}$ to $6^{\circ} \mathrm{C}$ [16] [17] [18] [19]. An unusually intense SST cooling of $10.8^{\circ} \mathrm{C}$ was even observed when typhoon Kai-Tak passed over the NSCS [20]. Leipper [21] and Shay, Goni and Black [17] reveal that the presence of ocean cold or warm features could impact TC-induced SST cooling and then the intensification of TCs. In warm ocean, e.g. warm boundary currents or warm eddies, ocean upper mixed layers are deep and the associated ocean heat contents relative to the $26^{\circ} \mathrm{C}$ isotherm often exceed $100 \mathrm{~kJ} / \mathrm{cm}^{2}$, which 
would reduce the TC-induced SST cooling, and hence provide more energy to fuel TCs [15] [17] [22]. In contrast, in the cold features or eddies region, shallow mixed layers and less ocean heat content would induce larger SST cooling and contribute to rapid weakening of TCs [23] [24]. However, few studies have been made to investigate the role of the pre-existing summer upwelling of NSCS in TCs self-induced SST cooling. In this study, the hydrographic measurements in the NSCS are firstly analyzed during the typhoon season to elucidate the characteristics of the upwelling process in the NSCS (Section 3). Then a one-dimensional mixed model was used to investigate the interplay of the upwelling and TC-induced SST cooling in the NSCS (Section 4), and conclusions are given in Section 5.

\section{Datasets}

The best-track data from the Joint Typhoon Warning Center (JTWC) were used to calculate the track and frequency of TC occurrence in the NSCS. The analysis mainly focuses on the peak season (June-September) of TCs during the period 1960-2010 since the satellite monitoring of weather events became routine from the 1960s onward. The persistent signals of upwelling in the NSCS are detected by the climatological Advanced Very High Resolution Radiometer (AVHRR) sea surface temperature (SST) images during 1985-2010 with a monthly interval. To further understand the vertical structures of upwelling of the NSCS, in situ observations, which obtained from the "908" Special Marine Survey and the South China Sea Open Cruise by the South China Sea Institute of Oceanology, Chinese Academy of Science for July 2006 and August 2007 are also used.

\section{PWP Model}

To estimate the role of NSCS pre-existing upwelling in TCs induced SST cooling, a one-dimensional (1D) mixed layer model of Price-Weller-Pinkel [16] is used. PWP model has a homogeneous mixed layer with uniform temperature, salinity, and velocity on top of the mixed layer base. In the PWP model, turbulent mixing occurrence involves three stability criteria: static instability, bulk and gradient Richardson number mixing. The critical bulk and gradient Richardson numbers are set to 0.65 and 0.25 according to Price et al. [16] and Price [13], respectively. In this work, two experiments are conducted with the model forcing by the same winds, precipitation, evaporation and surface heat fluxes but with different ocean initial temperature-salinity profiles. One is used the pre-typhoon temperature-salinity profiles from the non-upwelling region, which is a representative of no upwelling; the other is from the upwelling region, which denotes the presence of upwelling. For each experiment, the typhoon-induced SST cooling is estimated progressively with the increase of wind speed from 30 to $65 \mathrm{~m} / \mathrm{s}$, with $5 \mathrm{~m} / \mathrm{s}$ interval. Experiments are run under various translation speeds (Uh) ranging from 2 to $30 \mathrm{~m} / \mathrm{s}$ because the typhoon-induced SST cooling is not only a function of wind speed, but also a function of Uh [16]. 


\section{Results}

\subsection{Observed Summer Upwelling in the NSCS}

Generally, when upwelling occurs, colder, higher saline and nutrient-enriched water rises from the deeper layer, thus the lower temperature and higher salinity in the surface and subsurface water are good indicators of the upwelling [1] [6]. During the Asian summer monsoon season (June-September), a wide range of upwelling takes place in the NSCS, causing a local SST cooler about $1^{\circ} \mathrm{C}-2^{\circ} \mathrm{C}$ than that of the adjacent waters, can be seen from the climatological mean satellite SST (Figure 1). The cold waters cover almost half of the NSCS from the northeast of Hainan Island to the western of Taiwan Strait. Figure 2 further gives a detailed view of the upwelling, showing SST variation on an individual month from June to September. The upwelling occurs firstly in June in response to prevail southwesterly monsoon with cold SST first appearing on the east of Hainan Island, Shantou Coast, and the west of Taiwan Strait in June and then moving southeastward following the maximum offshore wind. This cold SST spreads over a larger area to the east of the NSCS in Jul, and then decays gradually in September, roughly coincident with that of typhoon from June through October, during which 1463 TCs form, accounting for almost $75 \%$ of the total TCs in the WNP and the SCS during the period of 1945-2010 (Figure 3).

The pronounced upwelling in the NSCS is also detected by in-situ hydrographic measurements (Figure 4 and Figure 5). Both the isotherms and isohalines are uplifted toward inshore subsurface. The strong upwelling can be seen below the surface $(\sim 10 \mathrm{~m})$ near the shelf and $\sim 50 \mathrm{~m}$ in the interior of NSCS. The intensity and size of the upwelling is generally controlled by the strength of the

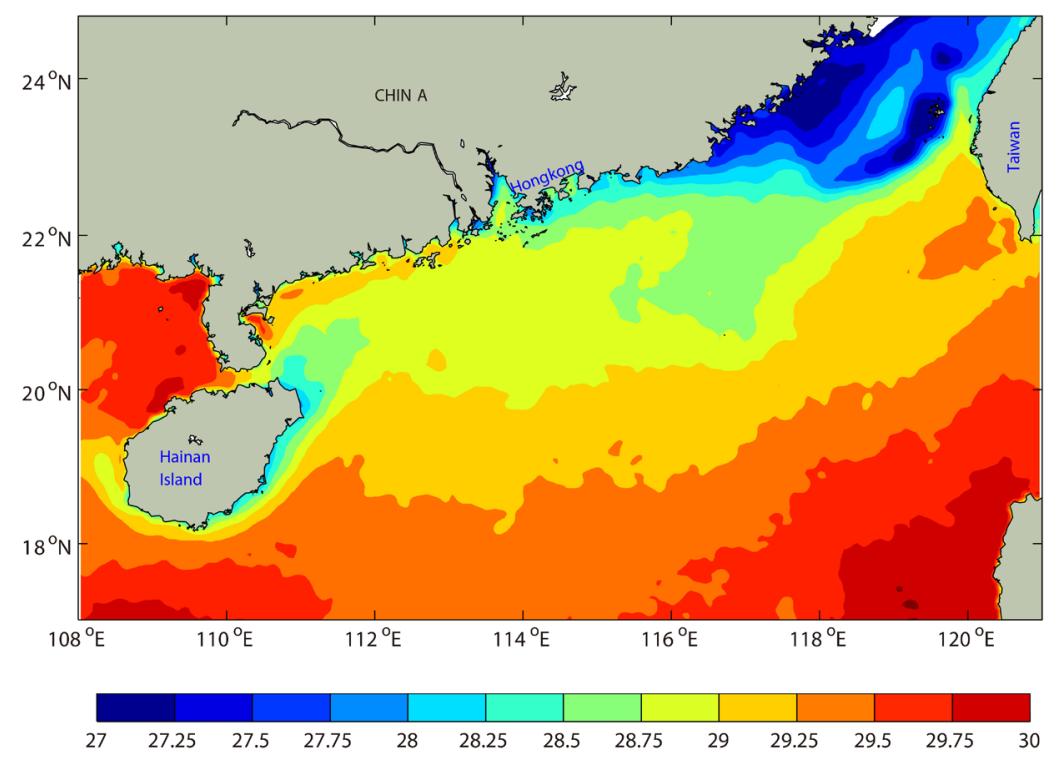

Figure 1. Climatological mean satellite sea surface temperature (SST in ${ }^{\circ} \mathrm{C}$ ) during June-September in the NSCS from 1985-2010. The Advanced Very High Resolution Radiometer (AVHRR) SSTs are taken from the Jet Propulsion Laboratory (JPL) of NASA with monthly interval on a $4 \mathrm{~km}$ grid. 

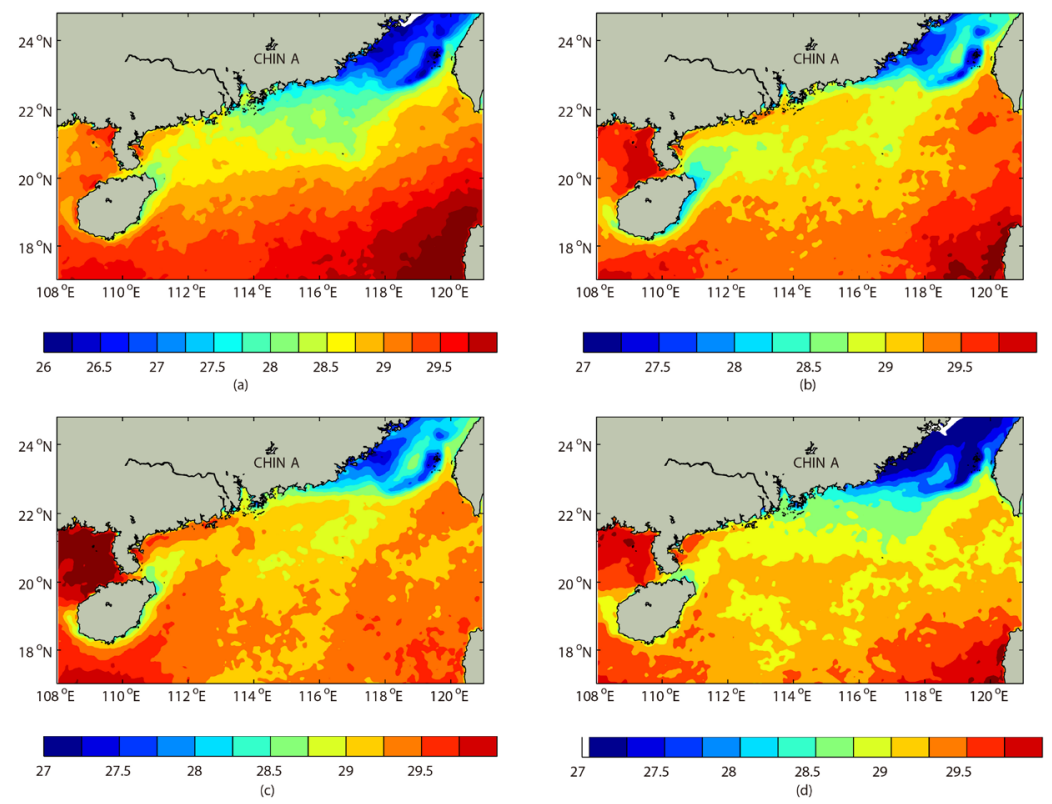

Figure 2. Climatological monthly mean SST $\left({ }^{\circ} \mathrm{C}\right)$ in the NSCS during upwelling season (June to September). (a) June.; (b) July; (c) August; (d) September.

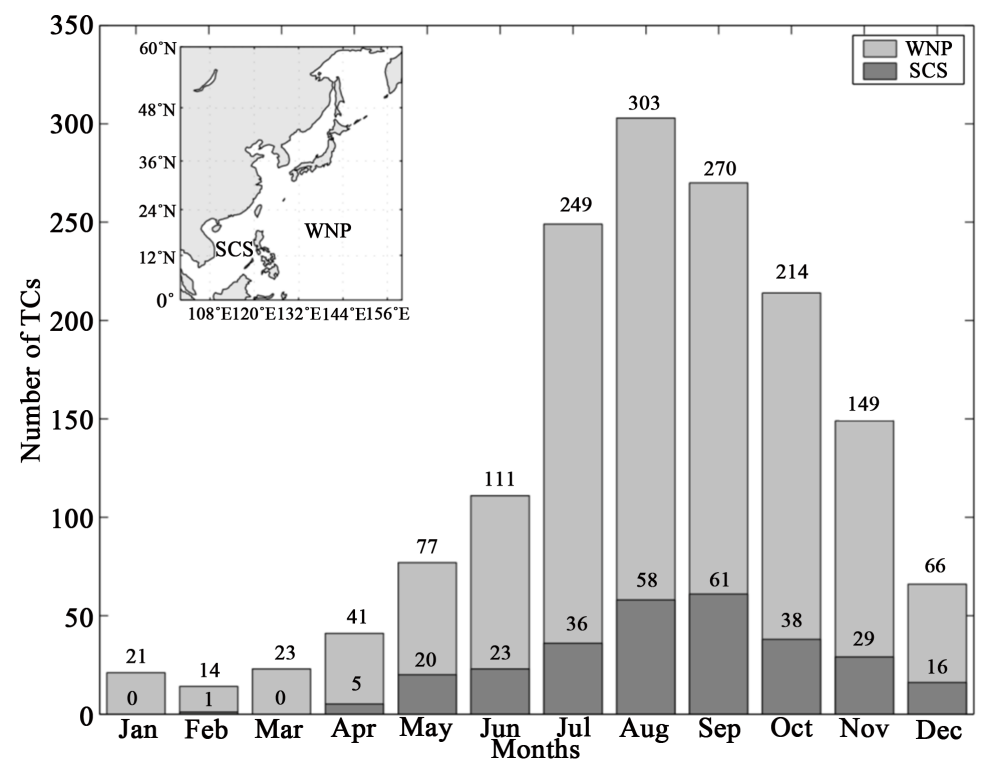

Figure 3. The monthly number of tropical cyclones formed in the western North Pacific (shaded gray) and in the South China Sea (shaded dark) during the period 1945-2010.

wind-driven surface Ekman transport and the interior shoreward return currents [4]. Analyses of observations and model outputs further reveal that although the local winds play important roles in the upwelling, the dynamic factor that controls the NSCS upwelling in different regions are quite different. In the Yuedong, the alongshore wind stress is the primary dynamic factor, while the local wind stress curl is the main contribution to the upwelling in the Qiongdong [7]. The detailed discussion about dynamic mechanisms is beyond the scope of this study. 


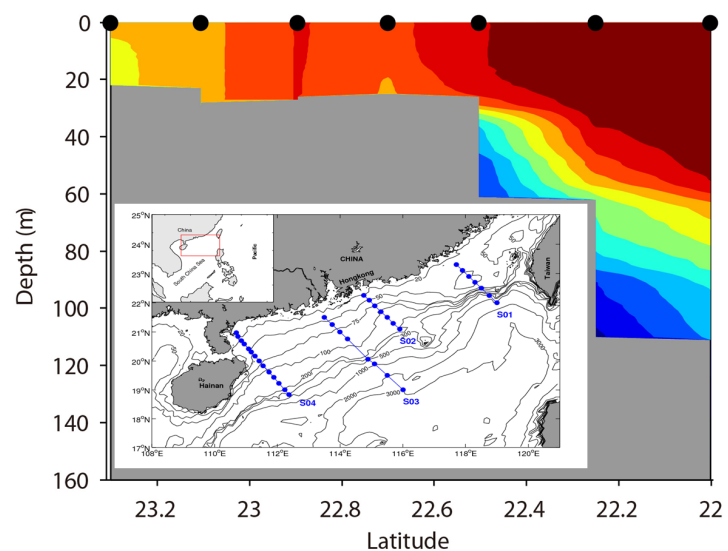

(a)

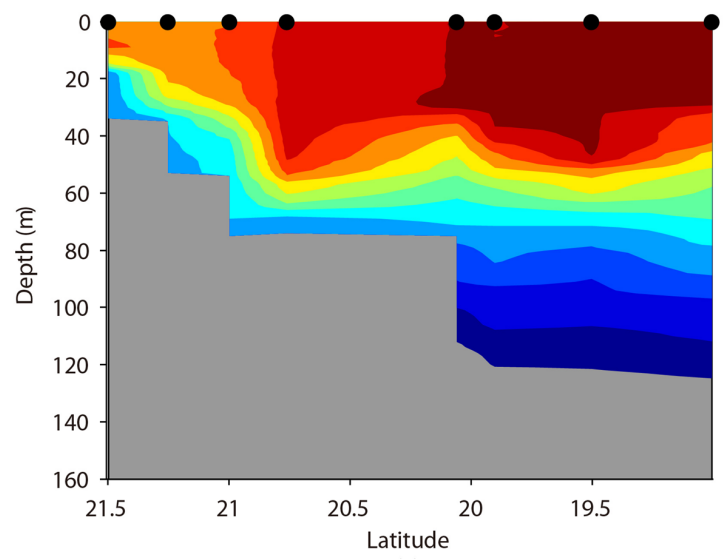

(c)
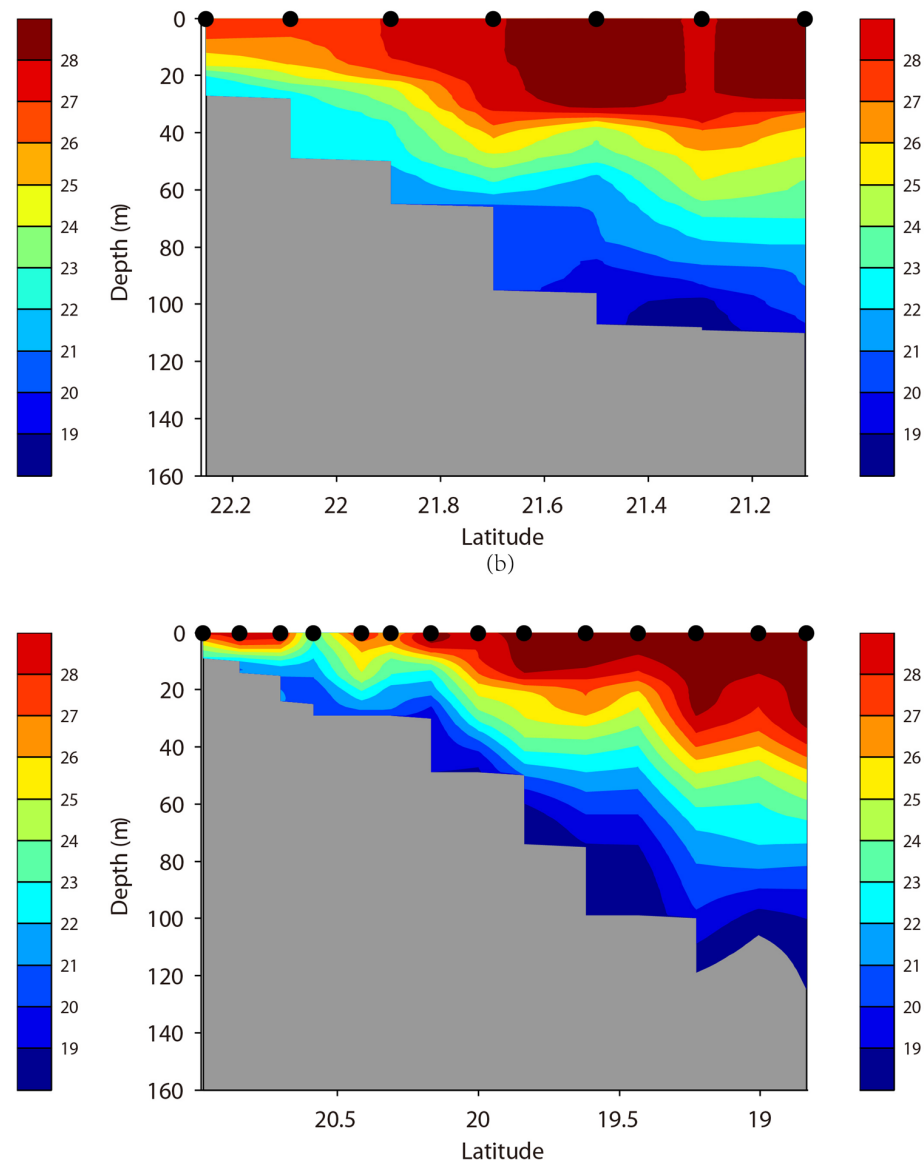

(d)

Figure 4. Vertical distributions of temperature along Sec1, Sec2, Sec3 and Sec4, whose locations are shown in Figure 2. In-situ data of Sec1, Sec2, Sec3 and Sec4 was collected during 21st-22nd July 2006. Blue lines with dots show the cruise route and stations.

(a) Temperature distribution $\left({ }^{\circ} \mathrm{C}\right)$ of S01; (b) Temperature distribution $\left({ }^{\circ} \mathrm{C}\right)$ of S01; (c) Temperature distribution $\left({ }^{\circ} \mathrm{C}\right)$ of S01; (d) Temperature distribution $\left({ }^{\circ} \mathrm{C}\right)$ of S01.

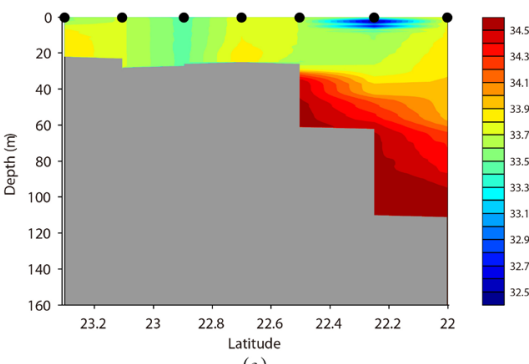

(a)

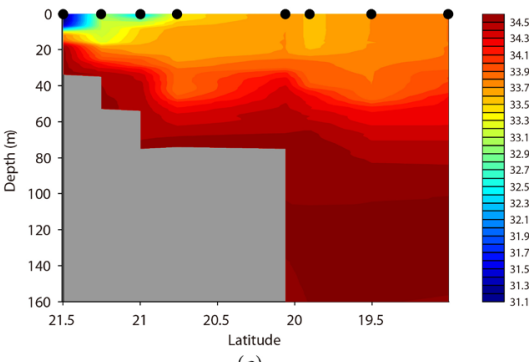

(c)
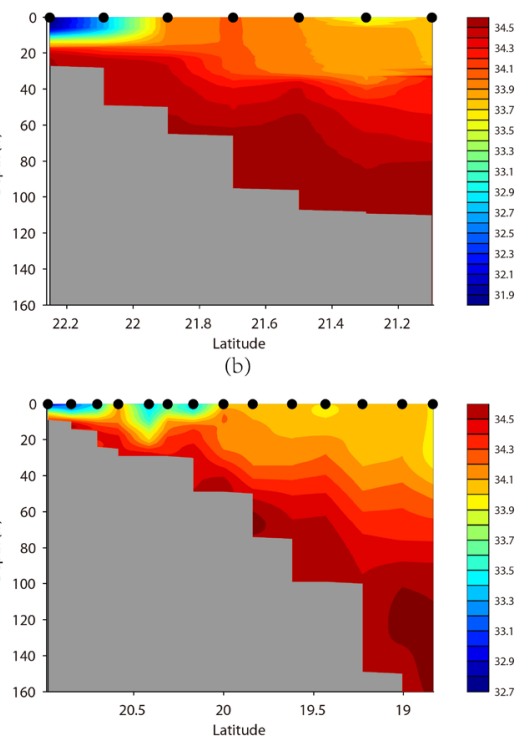

(d)

Figure 5. Same as Figure 2 but for salinity (psu). 
To summarize, the cooler SST associated with cooler subsurface waters is revealed in the upwelling region during summer season, which is roughly coincident with that of typhoon and motivates us to understand its possible relationship with typhoon-induced SST cooling in the NSCS.

\subsection{Historical Typhoons Tracks}

TCs occurring in the SCS and northwestern Pacific move frequently westward to the NSCS [11] [12]. Examples of individual tracks of TCs reveal that typhoon often pass directly through the upwelling regions of the NSCS. It can be seen from Figure 6(a) that 25 typhoons with their maximum wind speeds of 64 knots or greater pass over the region of upwelling (blue lines) and 10 do not (cyan lines) during 1960 to 1965. As typhoon strength increases (Figures 6(b)-(d)), an increasing percentage of typhoons passes through the upwelling region: for the period of 1960 to $1965,78 \%$ of the 14 typhoons that attained maximum wind speeds greater than $96 \mathrm{knots}$ passed directly over the historical region of the upwelling, whereas only $12 \%$ never passed over the upwelling regions (Figure 6(c)). Table 1 shows all the typhoon tracks with maximum wind speeds $>64$ knots for the period of $1960-2010$. From Table 1, we can see that over $60 \%$ of

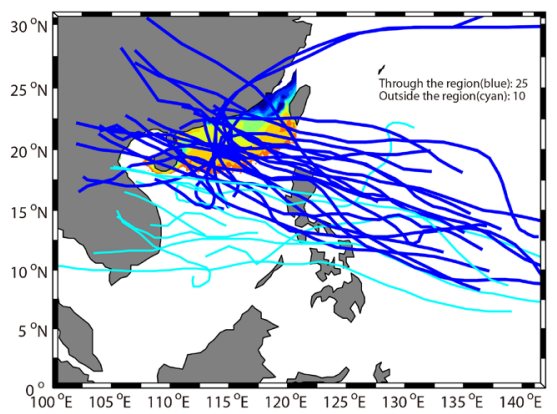

(a)

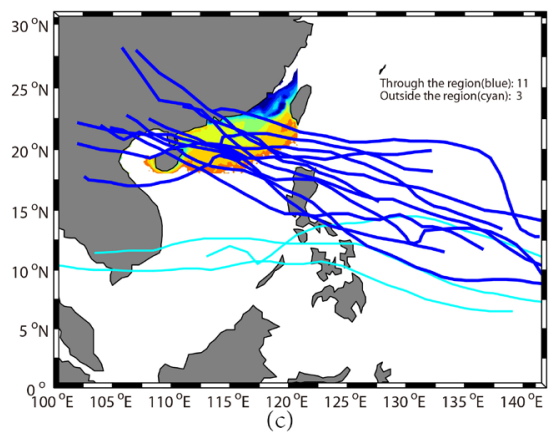

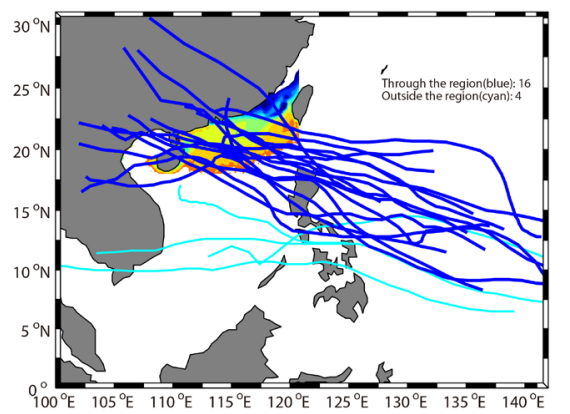

(b)

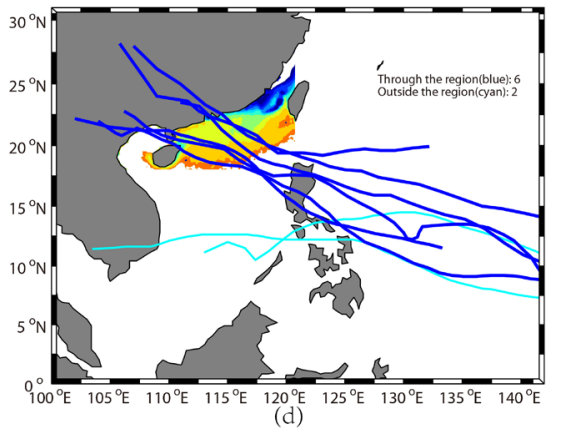

Figure 6. The 1960 to 1965 typhoon tracks for tropical cyclone (TC) that attained maximum wind speeds of $64 \mathrm{kt}$ or greater. The historical average extent of the upwelling in the continental shelf of northern South China Sea during TY season (Figure 2) is shown in rectangle. TC tracks passing through (outside) the upwelling region are indicated by blue (cyan) lines. TCs initially travel westward. The tropical cyclone category is defined based on Saffir-Simpson scale. (a) Typhoon with maximum wind speeds $\geq 64$ knots during 1960-1965; (b) Typhoon with maximum wind speeds $\geq 83$ knots during 1960-1965; (c) Typhoon with maximum wind speeds $\geq 96$ knots during 1960-1965; (d) Typhoon with maximum wind speeds $\geq 113$ knots during 1960-1965. 
Table 1. The distribution of 1960-2010 Typhoons by category within each location. Example of individual Typhoon tracks show that typhoon often pass directly through the historic region of NSCS upwelling.

\begin{tabular}{cccccc}
\hline Time & \multicolumn{2}{c}{ Through upwelling region } & \multicolumn{2}{c}{ Outside upwelling region } & All typhoons \\
\hline $1960-2010$ & No. & No./Total & No. & No./Total & Total \\
\hline Cat1 $(64-82 \mathrm{kt})$ & 71 & $65 \%$ & 38 & $35 \%$ & 109 \\
Cat2 $(83-95 \mathrm{kt})$ & 32 & $69 \%$ & 14 & $31 \%$ & 46 \\
Cat3 (96 - 113 kt) & 19 & $67 \%$ & 9 & $33 \%$ & 28 \\
Cat 4 (114- 135 kt) & 31 & $63 \%$ & 18 & $37 \%$ & 49 \\
Cat 5 (>135 kt) & 14 & $66 \%$ & 7 & $33 \%$ & 21 \\
\hline
\end{tabular}

TCs with maximum wind speeds $>64$ knots pass over the upwelling region, revealing that most of the destructive TCs may be directly influenced by ocean-atmosphere interaction in the upwelling region just prior to reaching the Southern China.

\section{Role of NSCS Upwelling in TC-Induced SST Cooling}

Does the pre-existing upwelling of NSCS have any role in TC-induced SST cooling or it just acts as a bystander? To answer this question, two experiments are designed using PWP model with the same forcing of winds, precipitation, evaporation and surface heat fluxes but different ocean initial profiles. One uses the pre-typhoon temperature-salinity profiles from the non-upwelling region, which represents no upwelling (Figure 7 and Figure 9: green lines).The other uses the pre-typhoon temperature-salinity profiles from upwelling region, which denotes the presence of upwelling (Figure 7 and Figure 9: red lines). For each experiment, TC-induced SST cooling is estimated progressively with the increase of wind speed from 30 to $65 \mathrm{~m} / \mathrm{s}$ and with the translation speeds (Uh) ranging from 2 to $30 \mathrm{~m} / \mathrm{s}$.

TC-induced SST cooling estimations for the climatological and in-situ observed profiles (Figure 7 and Figure 9) are depicted in Figure 8 and Figure 10. To the southeast of the strip that far away the upwelling region, temperatures during typhoons season are consistently warm throughout the upper ocean, with the surface temperature almost reaching $29^{\circ} \mathrm{C}$ (Figure 7(a): red line). In comparison, upper ocean temperatures in the upwelling region (shaded region) are much cooler, averaging between $27^{\circ} \mathrm{C}$ and $28^{\circ} \mathrm{C}$ at the surface, and around $24^{\circ} \mathrm{C}$ down to $100 \mathrm{~m}$ (Figure 7(b): green line). Consequently, the typhoons passing over the upwelling region will encounter significantly cooler ocean temperatures when the mixing reaching down to $100 \mathrm{~m}$ depth into the ocean.

Typhoon's self-induced SST cooling using the PWP ocean mixed layer model based on above climatological profiles in the non-upwelling and upwelling region are shown in Figure 8(a) and Figure 8(b). From Figure 8(a) and Figure $8(b)$, we can see that under the same wind forcing ( $x$ axis) and translation speed, 


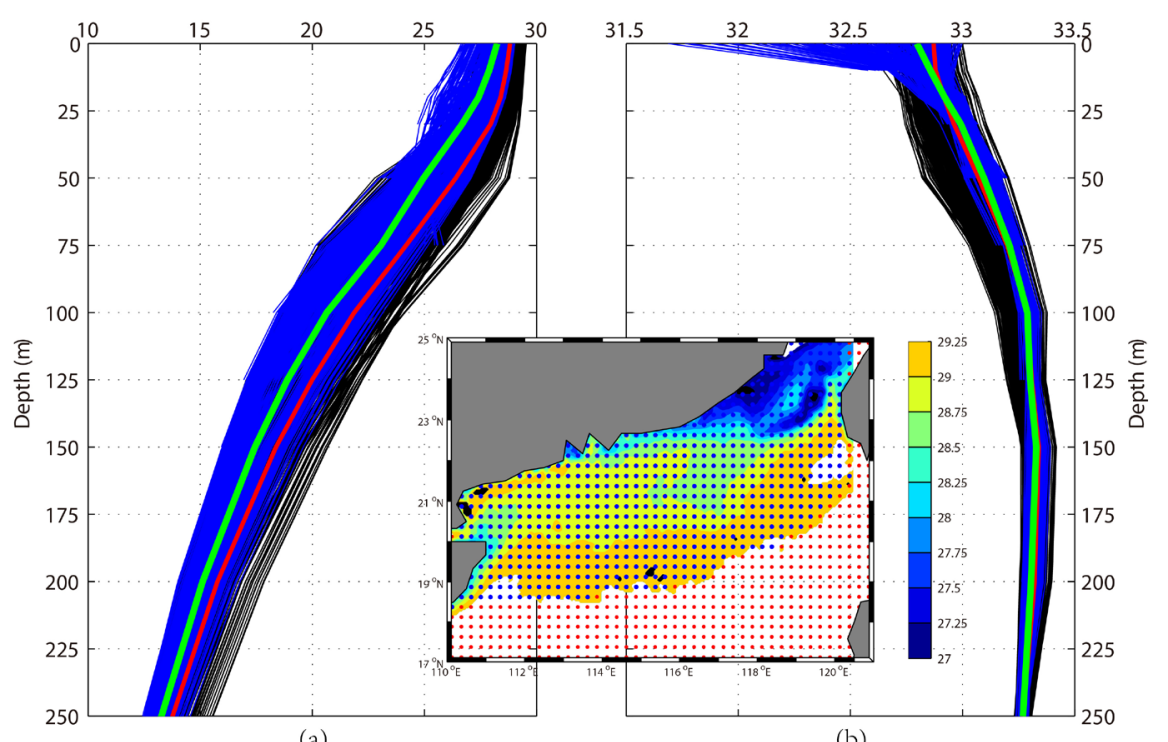

(a)

(b)

Figure 7. The temperature-salinity profiles and the mean in the upwelling region (blue and green lines) and non-upwelling region (black and red lines) based on WOA09 datasets. The blued dots with shaded of the subplot indicate the upwelling region, while the red dots indicate non-upwelling region. (a) Temperature profiles; (b) Salnity profiles.
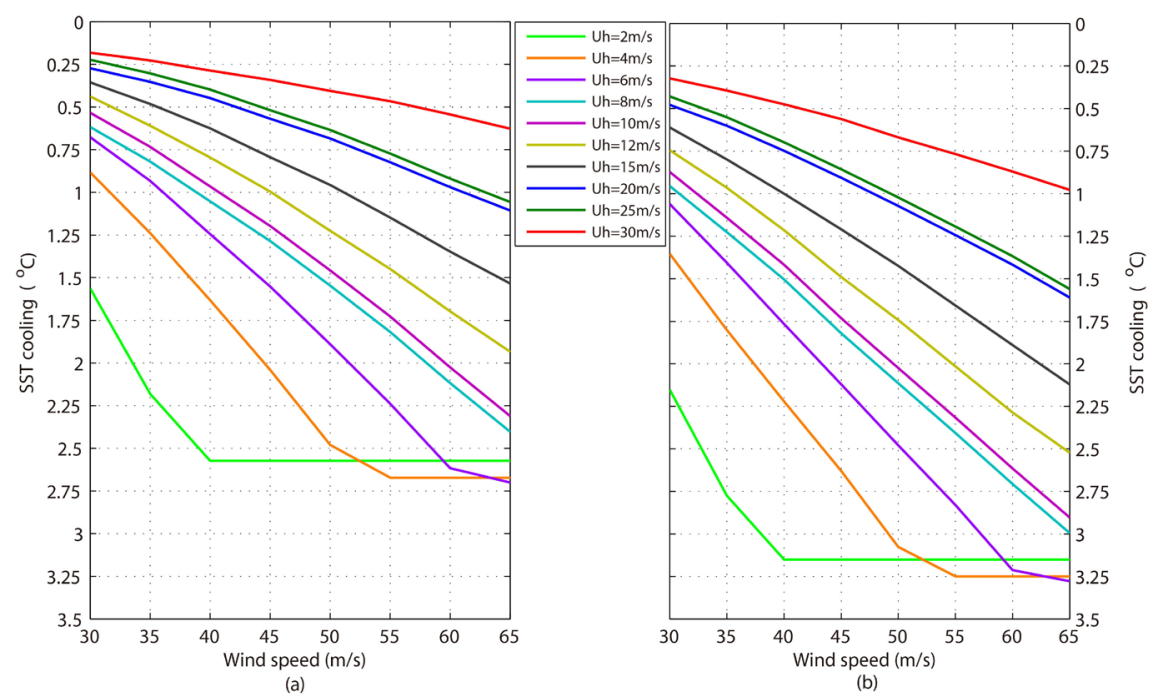

Figure 8. (a) Non-welling region, the TCs-induced sea surface temperature (SST) cooling in the non-upwelling region and (b) Upwelling region, the upwelling region based on WOA09 datasets for 10 different translation speeds (Uh) from 2 to $30 \mathrm{~m} / \mathrm{s}$ with the increase of wind speed from 30 to $65 \mathrm{~m} / \mathrm{s}$.

typhoon-induced SST cooling ( $y$ axis) is larger in the upwelling region (Figure $8(\mathrm{~b}))$ than that of non-upwelling region (Figure 8(a)). For example, for a typhoon moving at $U h=2 \mathrm{~m} / \mathrm{sand}$ wind speed $=30 \mathrm{~m} / \mathrm{s}$, typhoon induced cooling is $\sim 1.6^{\circ} \mathrm{C}$ in the regions without upwelling (Figure $8(\mathrm{a})$ : green line), but the corresponding SST cooling reach up to $2.1^{\circ} \mathrm{C}$ in the upwelling region (Figure 8(b): green line). This clearly shows that typhoon-induced SST cooling is more pronounced when typhoons pass over the region with the pre-existing upwel- 
ling. When typhoon moves faster, it induced SST cooling in the region of upwelling and non-upwelling are both reduced. This is because the faster the typhoon travels, the less action time on the upper ocean and the less pronounced SST cooling, consistent with the previous results [13] [14] [15].

The estimations based on in-situ profiles in the non-upwelling and upwelling region are also made and depicted in Figure 9 and Figure 10. Similar to the climatological profiles, temperature of upwelling region is significantly colder than that of non-upwelling region especially in the upper ocean from surface down to $80 \mathrm{~m}$ (Figure 9). The typhoon-induced SST cooling ( $y$ axis) is evidently larger

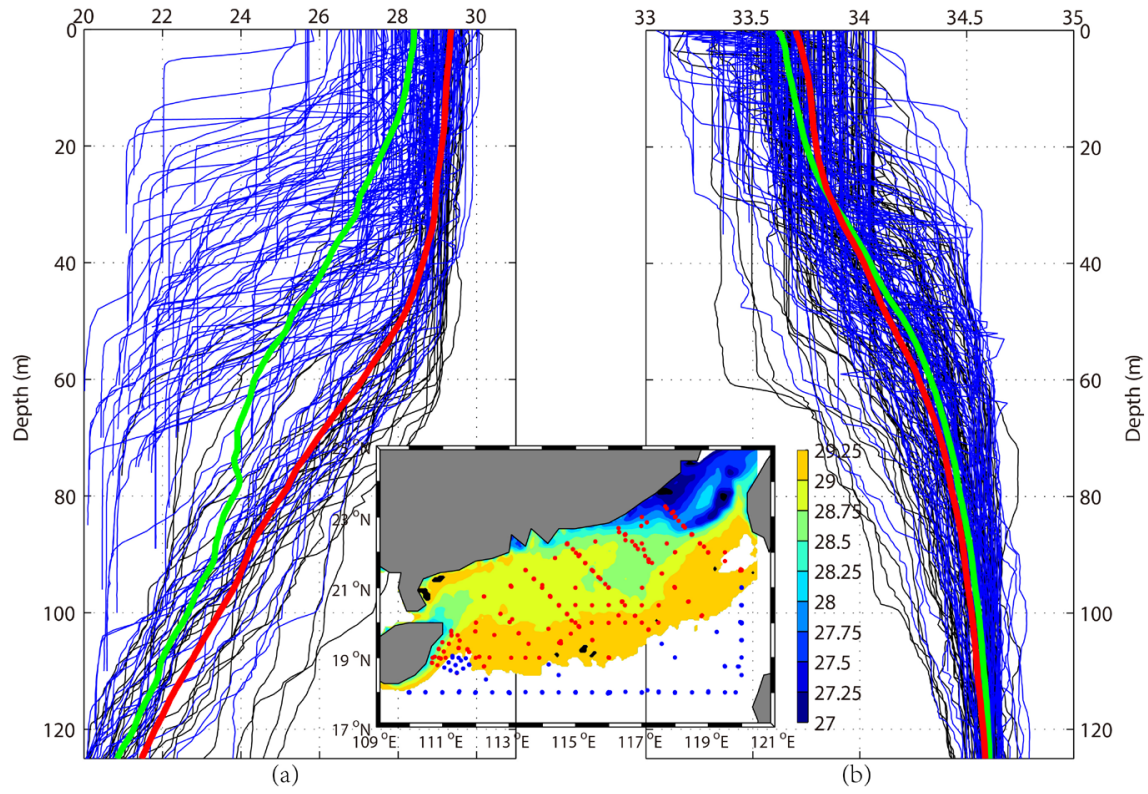

Figure 9. Same as Figure 8 but for the in-situ datasets. (a) Temperature profile; (b) Salinity profiles.
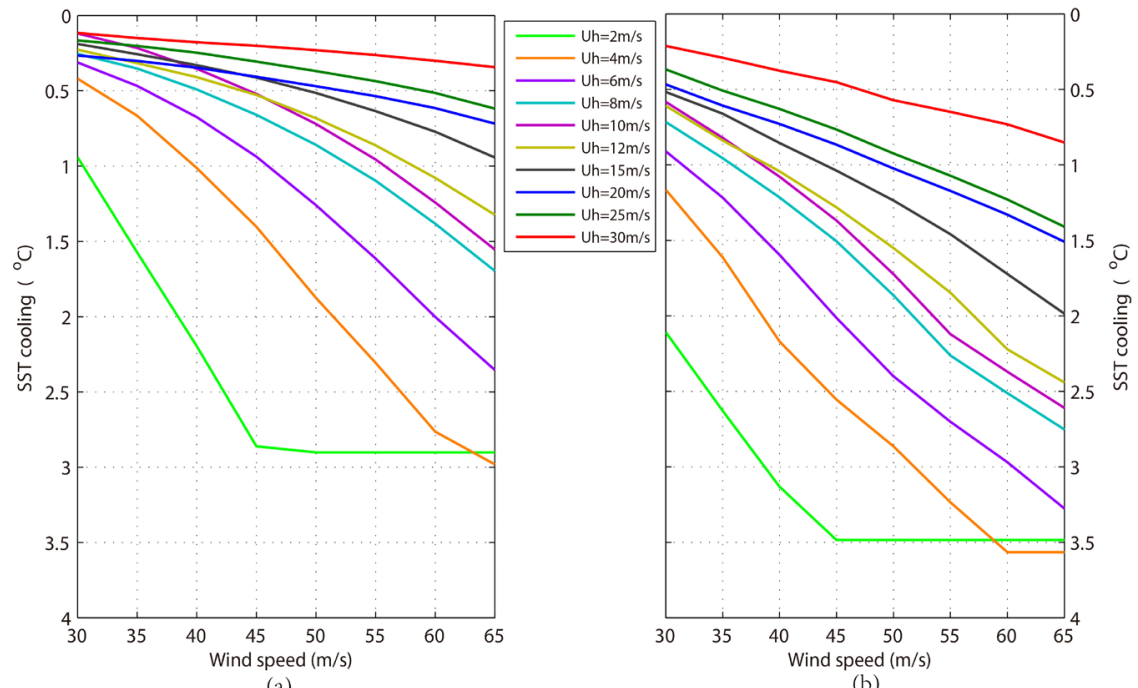

Figure 10. Same as Figure 9 but for the in-situ datasets. (a) Non-upwelling region; (b) Upwelling region. 
in the upwelling condition (Figure 10(b)) than that of non-upwelling (Figure 10(a)), consistent with that of climatological profiles. Since SST cooling would play a negative impact on TCs intensification [14], thus the upwelling of NSCS acts as a negative role in suppressing typhoons intensification before they made landfall at the Guangdong coastal areas.

In general, the pre-existent NSCS upwelling, which is forced by the summer monsoon, would modulate upper ocean temperature and salinity structures by bringing lower temperature waters from the deeper layer to the surface and subsurface. As typhoons move westward and pass over this upwelling region, the lower temperature of waters from the surface to the subsurface will be vertically mixing and induce larger SSTs cooling that is not favor for the intensification of typhoons.

\section{Conclusions}

Upwelling, as one of the most important physical processes linking to wind-driven currents and shelf topography in the coastal ocean, is commonly characterized by lower temperature and higher salinity in the upper ocean. The spreading of the upwelling in the NSCS exhibits a prominent seasonal cycle coinciding with the typhoon season. For the 1960 to 2010 time period, $65 \%$ of all categories 1 typhoon passed directly over the upwelling region of NSCS and strongly influenced by the upwelling before they made landfall in the Southern China. As ocean surface and subsurface temperatures may play a role in typhoon maintenance and intensification, understanding temperature variability of the upwelling region and its role in the rapid cooling of typhoon-induced SST is essential for forecast and prediction of typhoon.

The present study based on climatological and in situ observations and a one-dimensional (1D) mixed layer model of PWP shows that the relative cold oceanic temperatures associated with the NSCS upwelling, which is forced by the summer monsoon, could modulate upper ocean temperature by bringing deep lower temperature waters to the surface. This preexistent cold upper ocean temperature would amplify typhoon self-induced SST cooling when they pass over the upwelling region. The larger cooling of SST would pose a negative impact on typhoon maintenance and intensification and thus unfavorable for the intensification of typhoons. This result may be helpful to predict typhoon intensification since there has over $65 \%$ of typhoons that pass through this upwelling region, and more research needs to be carried out using more observations and more complex models.

\section{Acknowledgements}

This study is partly supported by the Marine Science and Technology Foundation of South China Sea Branch, State Oceanic Administration (grant 1447), the National Key Research and Development Program of China (2016YFC1401407), the Project of Global Change and Air-Sea interaction under contract No. 
GASI-03-IPOVAI-04, the National Natural Science Foundation of China (Grant No. 41731173 and 41776037), Distinguished Young Teachers of Fundamental Research Funds for the Central Universities (No.17lgzd11), and the China Scholarship Council (award to Xu Dazhi for 1 year's study abroad at Nansen Environmental and Remote Sensing Center).

\section{Conflicts of Interest}

The authors declare no conflicts of interest regarding the publication of this paper.

\section{References}

[1] Bakun, A. (1990) Global Climate Change and Intensification of Coastal Ocean Upwelling. Science, 247, 198-201. https://doi.org/10.1126/science.247.4939.198

[2] Barth, J.A., Menge, B.A., Lubchenco, J., et al. (2007) Delayed Upwelling Alters Nearshore Coastal Ocean Ecosystems in the Northern California Current. Proceedings of the National Academy of Sciences of the United States of America, 104, 3719-3724. https://doi.org/10.1073/pnas.0700462104

[3] Wang, B. and Wu, R. (1997) Peculiar Temporal Structure of the South China Sea Summer Monsoon. Advances in Atmospheric Sciences, 14, 177-194.

[4] Li, L. (1990) A Study on the Summer Upwelling in Shelf Waters West to Zhujiang River Mouth. Journal of Oceanography in Taiwan Strait, 9, 338-346.

[5] Xie, S.P., Xie, Q., Wang, D. and Liu, W.T. (2003) Summer Upwelling in the South China Sea and Its Role in Regional Climate Variations. Journal of Geophysical Research: Oceans, 108, 3261. https://doi.org/10.1029/2003JC001867

[6] Hu, J.Y., Kawamura, H. and Tang, D.L. (2003) Tidal Front around the Hainan Island, Northwest of the South China Sea. Journal of Geophysical Research: Oceans, 108, 3342. https://doi.org/10.1029/2003JC001883

[7] Jing, Z.Y., Qi, Y.Q. and Du, Y. (2011) Upwelling in the Continental Shelf of Northern South China Sea Associated with 1997-1998 El Nino. Journal of Geophysical Research: Oceans, 116, C02033. https://doi.org/10.1029/2010JC006598

[8] Wyrtki, K. (1961) Physical Oceanography of the Southeast Asia Waters. NAGA Report, 2, 1-195.

[9] Niino, H. and Emery, K.O. (1961) Sediments of Shallow Portions of East China Sea and South China Sea. Geological Society of America Bulletin, 72, 731-762.

[10] Guan, B.X. and Chen, S.J. (1964) Ocean Current System in East China Sea and South China Sea. Inst. of Oceanol., Chin. Acad. of Sci., Qingdao, China. (In Chinese)

[11] Wang, D., Zhuang, W., Xie, S.P., Hu, J., Shu, Y. and Wu, R. (2012) Coastal Upwelling in Summer 2000 in the Northeastern South China Sea. Journal of Geophysical Research: Oceans, 117, C04009. https://doi.org/10.1029/2011JC007465

[12] Wu, L., Wang, B. and Geng, S. (2005) Growing Typhoon Influence on East Asia. Geophysical Research Letters, 32, 109-127.

[13] Price, J.F. (2009) Metrics of Hurricane-Ocean Interaction: Vertically Integrated or Vertically Averaged Ocean Temperature? Ocean Science Discussions, 5, 351-368.

[14] Emanuel, K.A. (1999) Thermodynamic Control of Hurricane Intensity. Nature, 401, 665-669. https://doi.org/10.1038/44326

[15] Lin, I.I., Pun, I.F. and Wu, C.C. (2009) Upper Ocean Thermal Structure and the 
Western North Pacific Category-5 Typhoons Part II: Dependence on Translation Speed. Monthly Weather Review, 137, 3744-3757. https://doi.org/10.1175/2009MWR2713.1

[16] Price, J.F., Weller, R.A. and Pinkel, R. (1986) Diurnal Cycling: Observations and Models of the Upper Ocean Response to Diurnal Heating, Cooling, and Wind Mixing. Journal of Geophysical Research, 91, 8411-8427. https://doi.org/10.1029/JC091iC07p08411

[17] Shay, L.K., Goni, G.J. and Black, P.G. (2000) Role of a Warm Ocean Feature on Hurricane Opal. Monthly Weather Review, 128, 1366-1383.

[18] Jacob, S.D. and Shay, L.K. (2003) The Role of Oceanic Mesoscale Features on the Tropical Cyclone Induced Mixed Layer Response. Journal of Physical Oceanography, 33, 649-676. https://doi.org/10.1175/1520-0485(2003)33<649:TROOMF>2.0.CO;2

[19] Liu, S., Sun, L., Wu, Q., et al. (2017) The Responses of Cyclonic and Anticyclonic Eddies to Typhoon Forcing: The Vertical Temperature-Salinity Structure Changes Associated with the Horizontal Convergence/Divergence. Journal of Geophysical Research, 122, 4974-4989. https://doi.org/10.1002/2017JC012814

[20] Chiang, T.L., Wu C.R. and Oey, L.Y. (2011) Typhoon Kai-Tak: An Ocean's Perfect Storm. Journal of Physical Oceanography, 41, 221-233.

[21] Leipper, D.F. and Volgenau, D. (1972) Hurricane Heat Potential of the Gulf of Mexico. Journal of Physical Oceanography, 2, 218-224. https://doi.org/10.1175/1520-0485(1972)002<0218:HHPOTG>2.0.CO;2

[22] Schade, L.R. and Emanuel, K.A. (1999) The Ocean's Effect on the Intensity of Tropical Cyclones: Results from a Simple Coupled Atmosphere-Ocean Model. Journal of the Atmospheric Sciences, 56, 642-651. https://doi.org/10.1175/1520-0469(1999)056<0642:TOSEOT >2.0.CO;2

[23] Walker, N.D., Leben, R.R. and Balasubramanian, S. (2005) Hurricane-Forced Upwelling and Chlorophyll a Enhancement within Cold-Core Cyclones in the Gulf of Mexico. Geophysical Research Letters, 32, L18610.

[24] Jaimes, B., Shay, L.K. and Uhlhorn, E.W. (2013) Enthalpy and Momentum Fluxes during Hurricane Earl Relative to Underlying Ocean Features. Monthly Weather Review, 143, 111-131. 